Article

\title{
AFM Analyses of 3XXX Series Al Alloy Reinforced with Different Hard Nanoparticles Produced in Liquid State
}

\author{
Verónica Gallegos-Orozco ${ }^{1}$, Audel Santos-Beltrán ${ }^{1, *}$, Miriam Santos-Beltrán ${ }^{1}$, \\ Ivanovich Estrada-Guel ${ }^{2}$, Iza Ronquillo-Ornelas ${ }^{1}{ }^{10}$, José Brito-Chaparro ${ }^{1}$ \\ and Ricardo Carbajal-Sanchez ${ }^{1}$ \\ 1 Departamento de Nanotecnología, Universidad Tecnológica de Chihuahua Sur, Km. 3.5 Carr Chihuahua \\ Aldama, C.P, Aldama 31313, Chih, Mexico; vgallegos@utchsur.edu.mx (V.G.-O.); msantos@utchsur.edu.mx (M.S.-B.); \\ ironquillo@utchsur.edu.mx (I.R.-O.); jbrito@utchsur.edu.mx (J.B.-C.); rcarbajal@utchsur.edu.mx (R.C.-S.) \\ 2 Departamento de Metalurgia e Integridad Estructural, Centro de Investigación en Materiales \\ Avanzados (CIMAV), Miguel de Cervantes No. 120, C.P, Chih 31109, Mexico; ivanovich.estrada@cimav.edu.mx \\ * Correspondence: audelsantos@gmail.com
}

Received: 26 November 2019; Accepted: 30 December 2019; Published: 8 January 2020

\begin{abstract}
In the present work, nanocomposites-based $3 X X X$ series $\mathrm{Al}$ alloy with three different types of hard nanoparticles, including $\mathrm{TiO}_{2}, \mathrm{C}$, and $\mathrm{CeO}_{2}$, were produced employing two techniques such as mechanical milling and stir-casting method in order to evaluate the viability of integration of the reinforcement in the $\mathrm{Al}$ matrix. The integration and dispersion capability of the reinforcement into the $\mathrm{Al}$ alloy (3xxx Series) matrix was evaluated, using a phase angle difference and surface roughness analyses by atomic force microscopy operated in both the contact mode (CM-AFM) and tapping mode (TM-AFM), respectively. The distribution profile of both rugosity and the phase angle shift was used to statically quantify the integration and dispersion of the reinforcement into the extruded samples, by using the root mean square (RMS) parameter and phase shift coupled with the events number (EN) parameter. Results from Atomic Force Microscopy (AFM) analyses were corroborated by X-ray diffractometry and scanning electron microscopy (SEM) and transmission electron microscopy (TEM). Microhardness tests were conducted to identify the mechanical properties of the composites in the extruded condition and their correlation with the microstructure. A close relationship was found between the microstructure obtained from the AFM and X-ray diffractometry (XRD) analyses and mechanical properties. Among all, the $\mathrm{C}$ reinforcement produced the major changes in the microstructure as well as the best integration and dispersion into the Al-alloy coupled with the best mechanical properties.
\end{abstract}

Keywords: recycled Al; nanocomposite; stir-casting; nanoparticles dispersion

\section{Introduction}

The industrial sector has been interested in new materials as composites, particularly the nanoparticulate-reinforced metal matrix composites (nano-MMC's). These materials offer some key advantages, including: relatively lower production costs, isotropic properties, and the possibility of using a conventional metal forming process such as rolling, extrusion, and forging for manufacturing different components or products [1-3]. The aerospace and automotive industries require these composites for key applications considering their combined high strength, low density, and high-temperature resistance characteristics. Nano-MMC's are materials consisting of a metallic matrix reinforced with hard and insoluble nanoparticles (e.g., oxides, carbides, and nitrides) with a size generally below $100 \mathrm{~nm}$. A significant relevance of these materials is the interaction of dislocations 
with hard nanoparticles. When added to other strengthening mechanisms as a solid solution, grain size reduction, strain hardening, and precipitation strengthening, which are generally found in nano-MMCs, results in a notable improvement of mechanical properties [4-6]. Other authors have reported that, with a small fraction of nano-sized hard particles, nano-MMCs could obtain similar or even much higher mechanical properties than micro-composites [7]. A low concentration of reinforcement also produces low agglomeration at the matrix [8].

The most cost-effective technique of all existing routes for the manufacture of metal matrix compounds is the liquid metallurgy technique, and it is divided into four main categories: pressure infiltration, stir casting, spray deposition, and in situ processing. The stir casting process has several important advantages compared to other routes, e.g., selection of different types of materials (matrix and hard nanoparticles) and a better control of particle-matrix interfacial bonding and matrix structure. The process is simple, low-cost, and flexible and can be applied in large-scale production processes and is suitable in manufacturing processes for near-net shape components [9-13]. Extrusion is a thermomechanical process where severe plastic deformation is produced and is generally used as secondary processing of particulate reinforced composites. This metal forming process promotes the breakup of particle agglomerates and reduce or eliminate the porosity. Each of these help to improve the mechanical properties of nano-MMCs [14].

The aluminum beverage cans are globally one of the most critical recycled products, and the process of recycling takes only $5 \%$ of the energy needed to produce new aluminum [15]. In order to take advantage that recycled aluminum can be readily available, this work was focused on knowing the feasibility of integrating different kinds of hard nanoparticles into the Al recycled matrix to increase their mechanical properties. Taken into account a difficulty in integrating nanoparticles into the aluminum matrix during the stir-casting process $[16,17]$, it was necessary to evaluate the microstructural changes produced after the extrusion process and determine the existence of hard nanoparticles into the recycled $\mathrm{Al}$ matrix. Nanocomposite-based recycled aluminum (3XXX Series Al alloy) of beverage cans with $\mathrm{TiO}_{2}, \mathrm{C}$, and $\mathrm{CeO}_{2}$ nanoparticles were fabricated using two techniques such as mechanical grinding and stir-casting, using $\mathrm{Mg}$ as an auxiliary element in the incorporation and dispersion of the reinforcing phase [18]. This kind of particle shows excellent mechanical properties for MMCs. $\mathrm{TiO}_{2}$ is an excellent option because of its good hardness, low density, high melting point, high wear resistance, and good chemical stability $[19,20]$. On the other hand, the C element, which is transformed into $\mathrm{Al}_{4} \mathrm{C}_{3}$ during the as cast and extrusion process, significantly improve mechanical properties such as yield strength, tensile strength, and Young's modulus [21]. Lastly, $\mathrm{CeO}_{2}$ addition greatly increase the hardness, tensile strength, yield strength, and ductility of composites in the as-cast condition $[22,23]$.

\section{Materials and Methods}

Different types of hard nanoparticles of $\mathrm{TiO}_{2}, \mathrm{C}$, and $\mathrm{CeO}_{2}$ with an average size of about 30 to $50 \mathrm{~nm}$ were used as a reinforcing material to increase the recycled Aluminum (3XXX Series Al alloy) matrix strength obtained from beverage cans. Mg powder was used as an auxiliary element the in introduction and dispersion of hard nanoparticles. Using a Spex 8000 mixer/mill in the argon atmosphere, a mixture of $0.5 \mathrm{~g}$ of $\mathrm{Mg}$ powder, and $6 \mathrm{~g}$ of powder in a weight ratio of metallic pure $\mathrm{Al} /$ hard nanoparticles of 3:1, were mixed during $5 \mathrm{~min}$ and milled using a milling ball to the powder weight ratio of 5:1 for $2 \mathrm{~h}$. The ball mill and vial used were made from hardened steel. The powder mixtures were pressed at a pressure of $10 \mathrm{MPa}$ under uniaxial loading in a hydraulic press during $20 \mathrm{~s}$ to get consolidated master compound packets.

An electric resistance furnace equipped with an agitator system of the graphite stirrer impeller was used for melting $200 \mathrm{~g}$ of a recycled Al beverage can. The master compound packets composed of pure $\mathrm{Al}$ and nanoparticles labeled as $\mathrm{Alp}-\mathrm{Mg}, \mathrm{Alp}-\mathrm{TiO}_{2}, \mathrm{Alp}-\mathrm{C}$, and $\mathrm{Alp}-\mathrm{CeO}_{2}$, were added in the form of a packet into the molten metal when the vortex was formed every $20 \mathrm{~s}$. The aluminum melted was stirred for $10 \mathrm{~min}$, at the constant rate of $650 \mathrm{rpm}$, at $800^{\circ} \mathrm{C}$, and poured into cast iron cylinder molds. The final content of $\mathrm{Mg}$ and the reinforcement particle in Al-alloy was $0.5 \mathrm{wt} . \%$ and $1 \mathrm{wt} . \%$, 
respectively. Each cylinder was hot extruded by using indirect extrusion at $550{ }^{\circ} \mathrm{C}$ where the work metal is forced to flow through a circular die. An extrusion relation of 25 was used under high pressure to produce bars of $10 \mathrm{~mm}$ in diameter and $500 \mathrm{~mm}$ of length. The samples were polished by sand papers with different grades (Grit 220,400, 600, 800, 1000, and 1200). Then, for obtaining a mirror finish, samples were polished using $1 \mu \mathrm{m}$ and $0.5 \mu \mathrm{m}$ alumina slurry. After that, samples were cleaned with distilled water using an ultrasonic cleaner for $5 \mathrm{~min}$ before studying under AFM.

The extruded samples were labeled as $\mathrm{Al} / \mathrm{Ref}, \mathrm{Al} / \mathrm{C}, \mathrm{Al} / \mathrm{CeO}_{2}$, and $\mathrm{Al} / \mathrm{TiO}_{2}$. Table 1 shows the limit of chemical composition of 3xxx series aluminum alloy that is known from the Aluminum Association. The master powder and extruded composites were studied by X-ray diffraction, Scanning Electron Microscopy (SEM), and Atomic Force Microscopy (AFM). Images of compositional variations were analyzed using WSXM software [24] (WSxM v4.0 Beta 9.3 version, Nanotec Electrónica S.L., Centro Empresarial Euronova 3, Madrid, Spain) recorded from a phase angle difference between the excitation force and the tip response in amplitude modulation of AFM. The diffraction profiles were measured by a Philips X'pert powder diffractometer using a Cu cathode $(\lambda=0.15406 \mathrm{~nm})$. The step size and step time were $0.02^{\circ}$ and $5 \mathrm{~s}$, respectively. The size of the reinforcement from the master compound powder after the milling process together with the crystallite size and micro deformation of the extruded composites were obtained from the analyses of the X-ray diffraction peaks by the Rietveld method. Scanning electron microscopy images were acquired by a cold field emission JEOL JSM-7401 F microscope (JEOL LTD, Akishima, Tokyo, Japan) working at 5 and $17 \mathrm{kV}$ to get images and elemental analysis, respectively. This SEM has an energy dispersive X-ray spectrometer (EDS) facility (Oxford Inca model, Oxford Instruments, High Wycombe, UK). Topography surface characterization was made using an atomic force microscopy tapping mode operated at $10 \mathrm{kHz}$ to $1 \mathrm{MHz}$ of the drive frequency range (Veeco Instruments, Inc., atomic force microscopy, Plainview, NY, USA). Transmission electron microscopy (TEM) characterization was performed using a transmission electron microscope (Philips CM-200 (Philips/FEI Company, Eindhoven, Netherlands) operating at $200 \mathrm{kV}$ ) equipped with a DX4 energy dispersive spectrometer (EDS) (EDAX Ltd., Mahwah, NJ, USA).

Table 1. Chemical composition of recycled aluminum.

\begin{tabular}{ccccccc}
\hline \multicolumn{7}{c}{ Weight Percent of Elements } \\
\hline $\mathrm{Al}$ & $\mathrm{Mn}$ & $\mathrm{Fe}$ & $\mathrm{V}$ & $\mathrm{Cu}$ & $\mathrm{Cr}$ & $\mathrm{Zn}$ \\
\hline Balance & 0.74 & 0.64 & 0.4 & 0.13 & 0.18 & 0.08 \\
\hline
\end{tabular}

\section{Results}

\subsection{Master Compound Samples Powder Characterization}

The XRD patterns from master compound samples after $2 \mathrm{~h}$ of milling are shown in Figure $1 \mathrm{a}$. The diffractions patterns show the presence of the $\mathrm{Al}, \mathrm{Mg}$, and the correspondent phase: $\mathrm{C}, \mathrm{CeO}_{2}$, and $\mathrm{TiO}_{2}$. The diffraction peak width broadening observed is a consequence of the decrease in the size of both crystallite of the $\mathrm{Al}$ matrix and reinforcement phase during the milling process. The average size of the reinforcement phase (integrated into the Al matrix of the master compound) was estimated from the Rietveld refinement, which is a detail of the diffraction pattern of the $\mathrm{Alp}-\mathrm{TiO}{ }_{2}$ sample from Rietveld refinement analysis is shown in Figure $1 \mathrm{~b}$. The average size of the reinforcement is shown in Table 2, and the average size of $\mathrm{C}$ and $\mathrm{CeO}_{2}$ reinforcement phase was around 65 and $40 \mathrm{~nm}$, respectively. The $\mathrm{TiO}_{2}$ phase's average size was $\sim 18 \mathrm{~nm}$.

Table 2. Reinforcement phase size from XRD analyses results.

\begin{tabular}{ccc}
\hline Phase & Average Size (nm) & Standard Deviation (SD) \\
\hline $\mathrm{C}$ & 64.9 & 0.18 \\
$\mathrm{CeO}_{2}$ & 40.6 & 0.25 \\
$\mathrm{TiO}_{2}$ & 18.2 & 0.63 \\
\hline
\end{tabular}




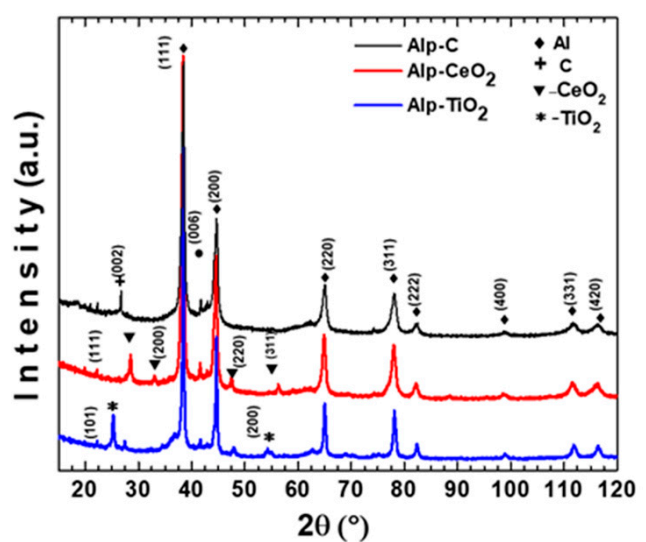

(a)

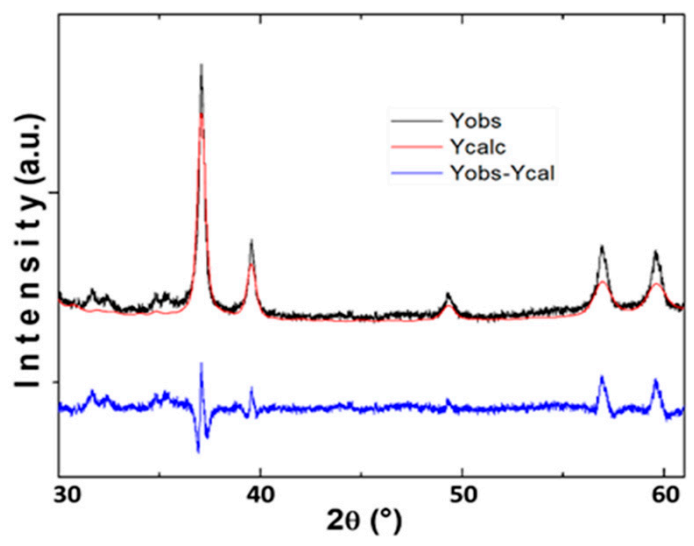

(b)

Figure 1. (a) XRD patterns from master compound samples after $2 \mathrm{~h}$ of milling; (b) Rietveld refinement of the Alp- $\mathrm{TiO}_{2}$ sample.

\subsection{XRD Characterization of Extruded Samples}

During the extrusion process, at higher rates of deformation, the rearrangement of dislocations during the recovery process coupled with the fine-sized reinforcement dispersion, induce the formation of a nanostructured state with a high presence of micro-strains (or high dislocations density) and reduced crystallite size. The reduction in grain size with increased content of reinforcement can be attributed to its distribution and the pinning effect [25-27]. X-ray diffraction patterns of composites after the extrusion process at $550{ }^{\circ} \mathrm{C}$ are shown in Figure 2. In general, all the patterns only show the $\mathrm{Al}$ phase with a preferential orientation of the grain at [111] planes along the extrusion direction. All diffraction peaks of samples show an evident broadening, which was the result of the presence of lattice micro-strains and the presence of reduced crystallite size. The average micro-strains values were evaluated from the X-ray diffraction patterns by using the Rietveld refinement method. From the analyses, we found the best refining results were obtained when only the micro-strains values were considered as the leading cause of the broad diffraction peaks. Therefore, the effect of crystallite size was neglected. Table 3 shows the micro-strains values and lattice parameter for each composite. A correlation between the reinforcement addition and lattice micro-strains values was observed. The samples with reinforcement content showed an evident increase in micro-strain values concerning the $\mathrm{Al} /$ Ref sample. Among all the samples, the $\mathrm{Al} / \mathrm{TiO}_{2}$ sample showed the highest micro-strain lattice value, which suggests the $\mathrm{TiO}_{2}$ reinforcement has a strong effect on the aluminum alloy matrix microstructure.

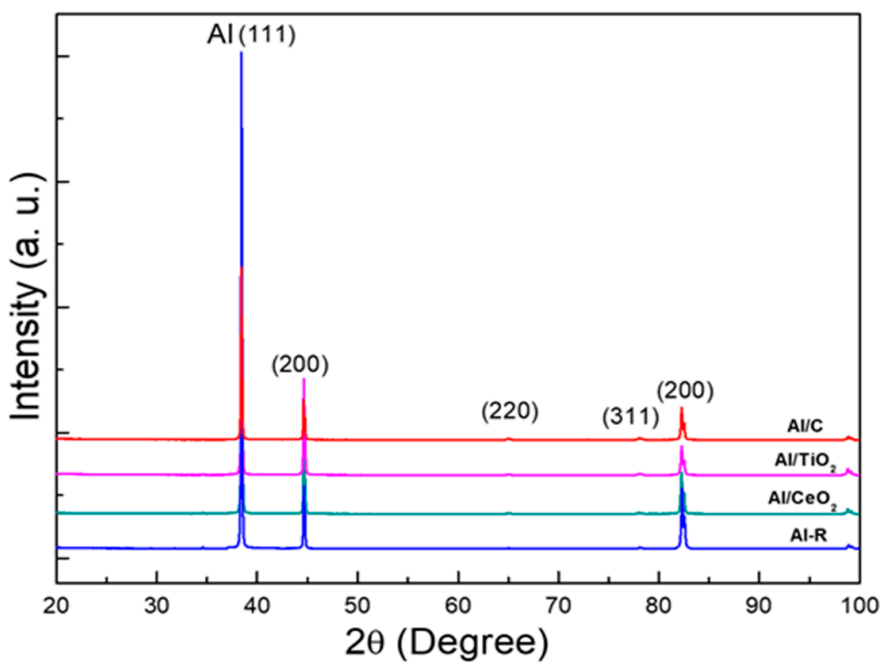

Figure 2. X-ray diffraction patterns of composites after the extrusion process at $550{ }^{\circ} \mathrm{C}$. 


\subsection{Extruded Samples AFM Topography Characterization}

The influence of particle dispersion on surface roughness is shown in AFM topography images and height distribution profiles of surface roughness (see Figures 3-6). In general, AFM topography images of samples show the presence of nano-crystallites mostly rounded shaped ranging mainly from 20 to above $100 \mathrm{~nm}$. Notably, for the Al/Ref sample, the height distribution profile (see Figure 3b) shows a bimodal topographic distribution, which is the product of a non-uniform topography. On the other hand, $\mathrm{Al} / \mathrm{CeO}_{2}, \mathrm{Al} / \mathrm{TiO}_{2}$, and $\mathrm{Al} / \mathrm{C}$ composite samples show a more uniform and refined topographic image with a distribution profile located at lower topography values. The height distribution profile of surface roughness was quantified by the RMS (Root Mean Square) roughness parameter, which is the square root of the distribution of surface height topography [28]. According to the results, the presence of the reinforcement produces smaller RMS values (if compared with the Al/Ref sample), which are the result of the refinement topography after the extrusion process. In fact, the RMS values correlate well with micro-strain lattice values found of the characterization of XRD carried out in extruded compounds (see Table 3). The $\mathrm{Al} / \mathrm{TiO}_{2}$ composite showed the smallest RMS and SD values, which results in uniform dispersion of fine particles of a similar size coupled with the presence of more uniform distribution of small crystallites.

Table 3. Micro-strain, topography roughness (RMS), and event number (EN) and the correspondent standard deviation (SD) values.

\begin{tabular}{cccccc}
\hline Composites & $\begin{array}{c}\text { Micro-strains } \\
\times \mathbf{1 0}^{-4} \mathbf{( \% )}\end{array}$ & $\begin{array}{c}\text { Topography } \\
\text { Roughness RMS } \\
(\mathbf{n m})\end{array}$ & $\begin{array}{c}\text { RMS } \\
(\mathbf{S D}, \mathbf{n m})\end{array}$ & $\begin{array}{c}\text { Event Number (EN) } \\
\text { (At 30 } \mathbf{0}^{\circ} \text { angle phase) }\end{array}$ & EN (SD) \\
\hline $\mathrm{Al} / \mathrm{Ref}$ & 1.4 & 12.79 & \pm 4.88 & $\sim 0$ & - \\
$\mathrm{Al} / \mathrm{C}$ & 5.1 & 8.54 & \pm 3.25 & 26,000 & \pm 3.78 \\
$\mathrm{Al} / \mathrm{CeO}_{2}$ & 5.3 & 8.69 & \pm 3.86 & 4700 & \pm 3.88 \\
$\mathrm{Al} / \mathrm{TiO}_{2}$ & 8.6 & 3.10 & \pm 1.29 & 17,800 & \pm 2.6 \\
\hline
\end{tabular}

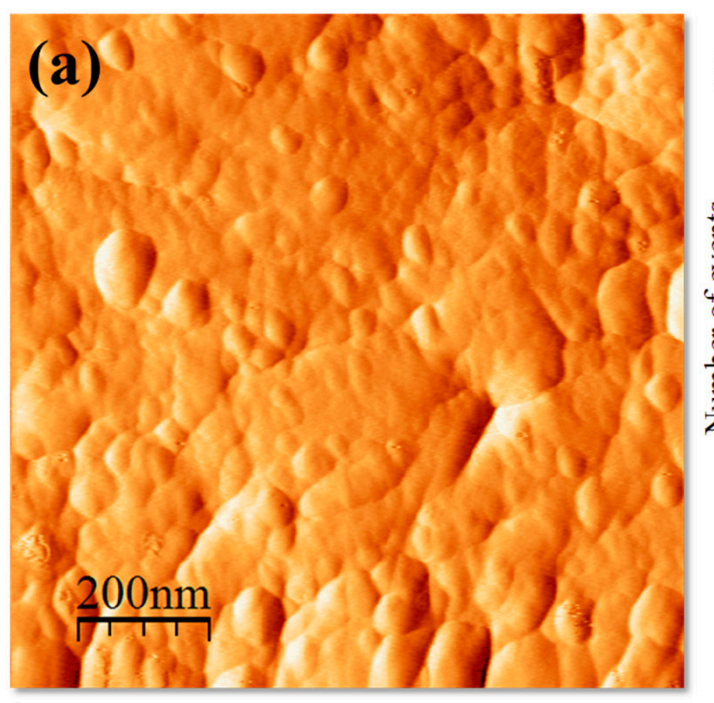

Figure 3. $\mathrm{Al} /$ Ref sample after the extrusion process: distribution profile of surface roughness.

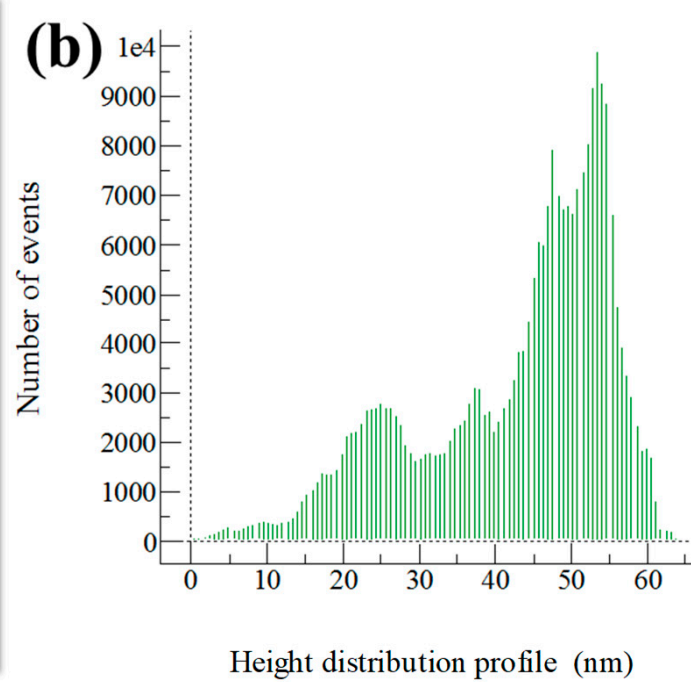

(a) AFM topography image and (b) height 

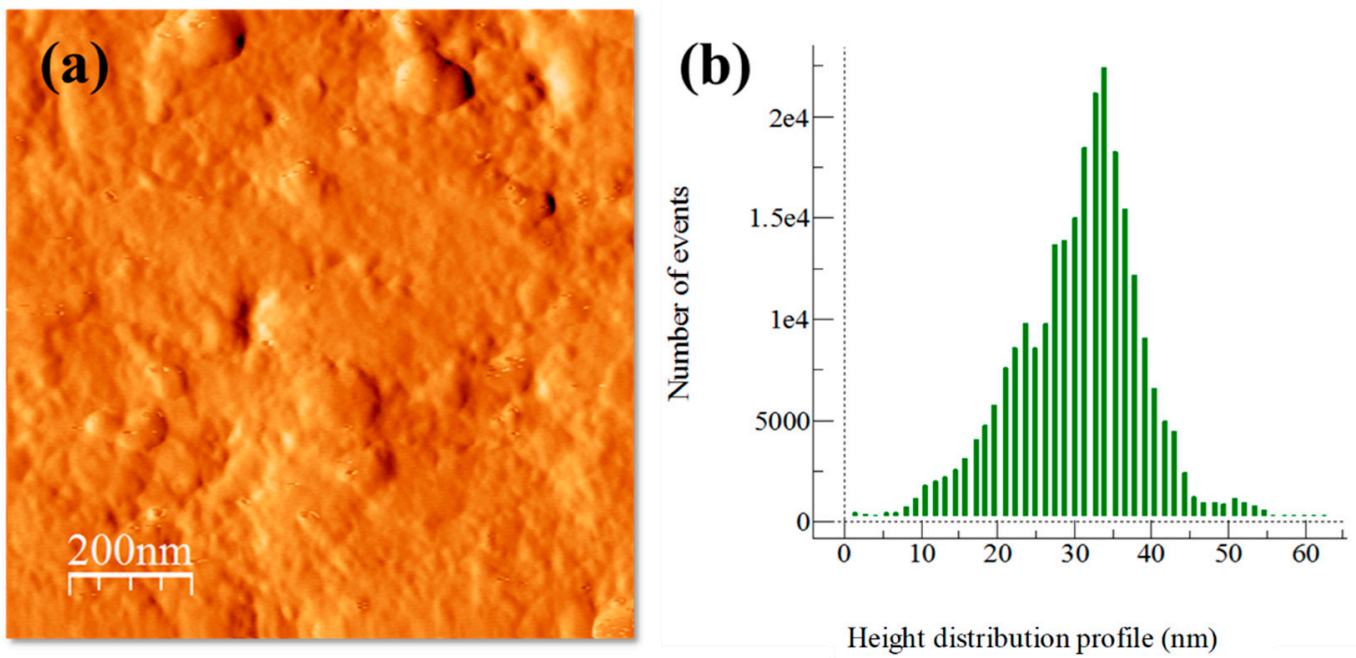

Figure 4. $\mathrm{Al} / \mathrm{CeO}_{2}$ composite sample after the extrusion process: (a) AFM topography image and (b) height distribution profile of surface roughness.
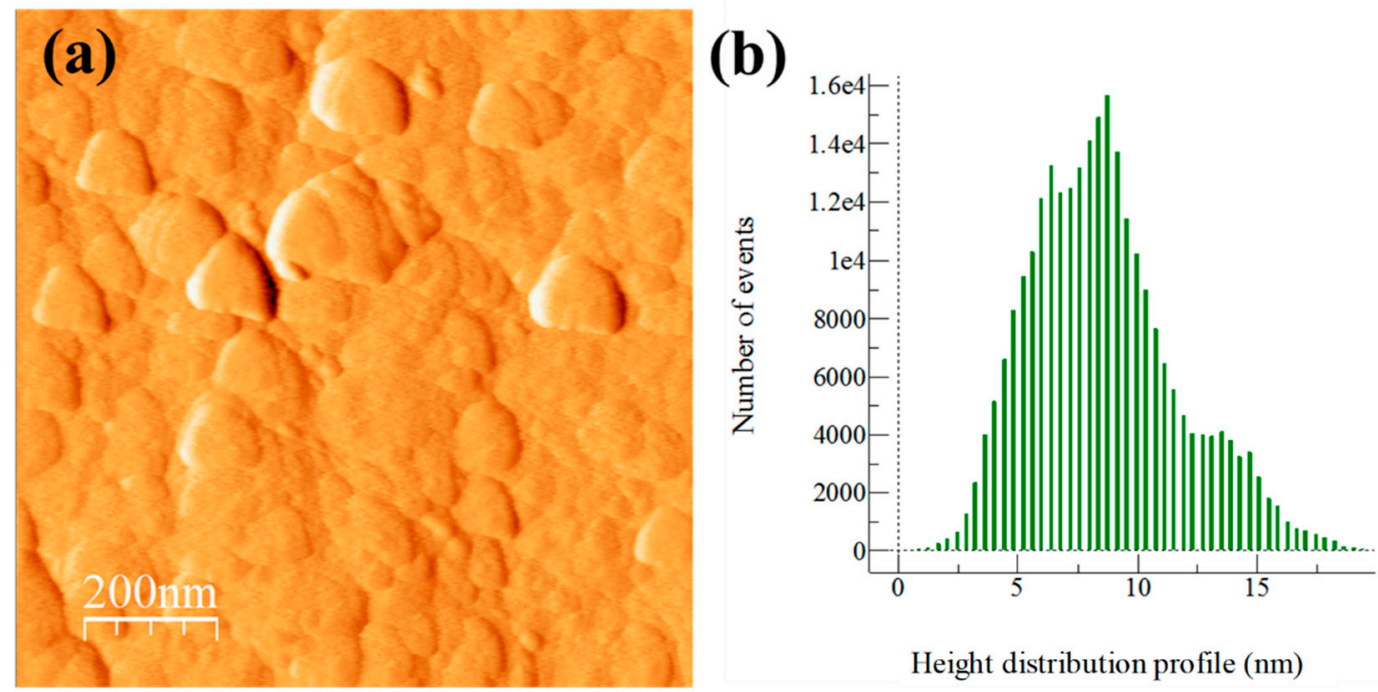

Height distribution profile (nm)

Figure 5. $\mathrm{Al} / \mathrm{TiO}_{2}$ composite after the extrusion process: (a) AFM topography image and (b) height distribution profile of surface roughness.
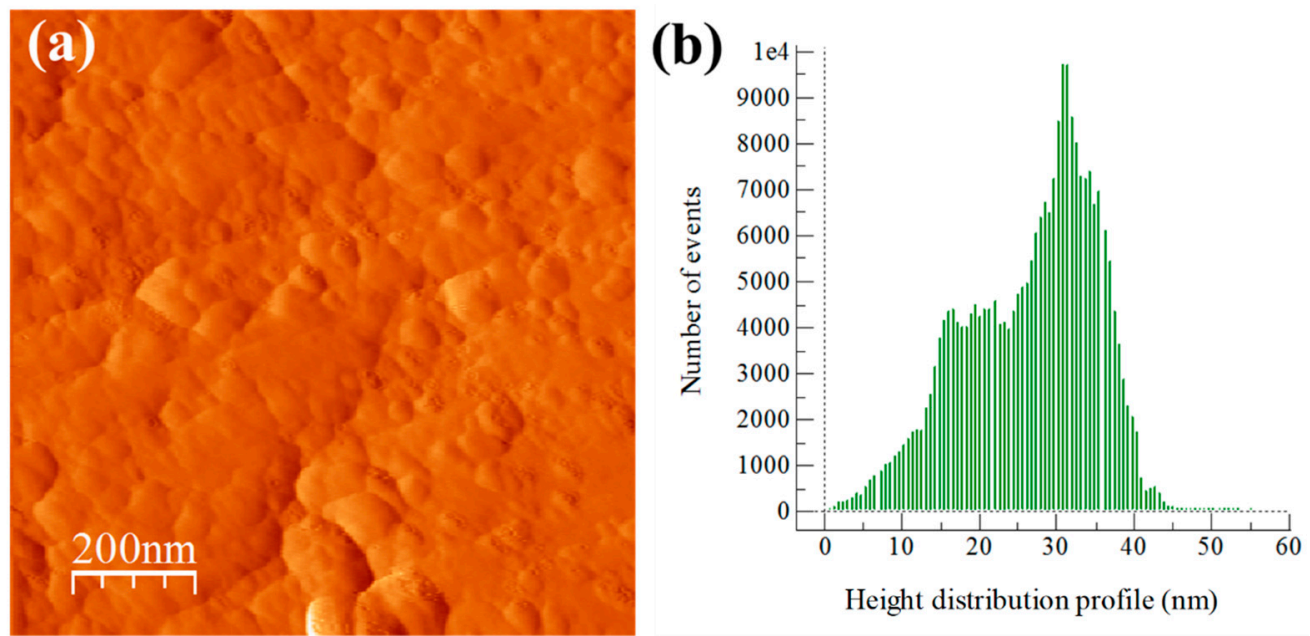

Figure 6. $\mathrm{Al} / \mathrm{C}$ composite after the extrusion process: (a) AFM topography image and (b) height distribution profile of surface roughness. 


\subsection{Master Compound Samples AFM Phase Characterization}

The integration and dispersion of the reinforcement were statistically quantified from the distribution profile of the phase obtained from AFM phase images. The distribution profile of the phase was first evaluated in the master compound with and without reinforcement content (see Figures 7 and 8), which was followed by the analysis of the extruded samples. The reinforcement phase was located at a phase angle similar to that found in the master compound. Images of compositional variations obtained using WSXM software are shown in Figures 7a and 8a for Alp-Mg and $\mathrm{Alp}^{-\mathrm{TiO}} 2$ master compound samples. Figures $7 \mathrm{~b}$ and $8 \mathrm{~b}$ show the degree distribution profile of the phase shift. The continuous line that crosses the clear areas in the phase images coupled with the corresponding distribution profile of the phase change (shown in the inset of Figures $7 \mathrm{~b}$ and $8 \mathrm{~b}$ ) shows the difference in the phase angle between the Al matrix and another phase. The Alp-Mg master compound sample image (see Figure 7a) shows the presence of clear zones of about $300 \mathrm{~nm}$ in size that could correspond to the $\mathrm{Mg}$ phase (not found on pure $\mathrm{Al}$ ), with a distribution profile of a phase shift peak located at $\sim 55^{\circ}$ (see the inset of Figure 7b). On the other hand, the $\mathrm{Alp}-\mathrm{TiO}_{2}$ master compound sample's phase image shows a topography with uniform, finely rounded grains and the presence of a phase (clear zone) that could correspond to the $\mathrm{TiO}_{2}$ phase located at the limit of grains (see Figure 8a). In this case, the peak is located at $\sim 35^{\circ}$ of the distribution profile's phase shift (see the inset of Figure $8 \mathrm{~b}$ ).
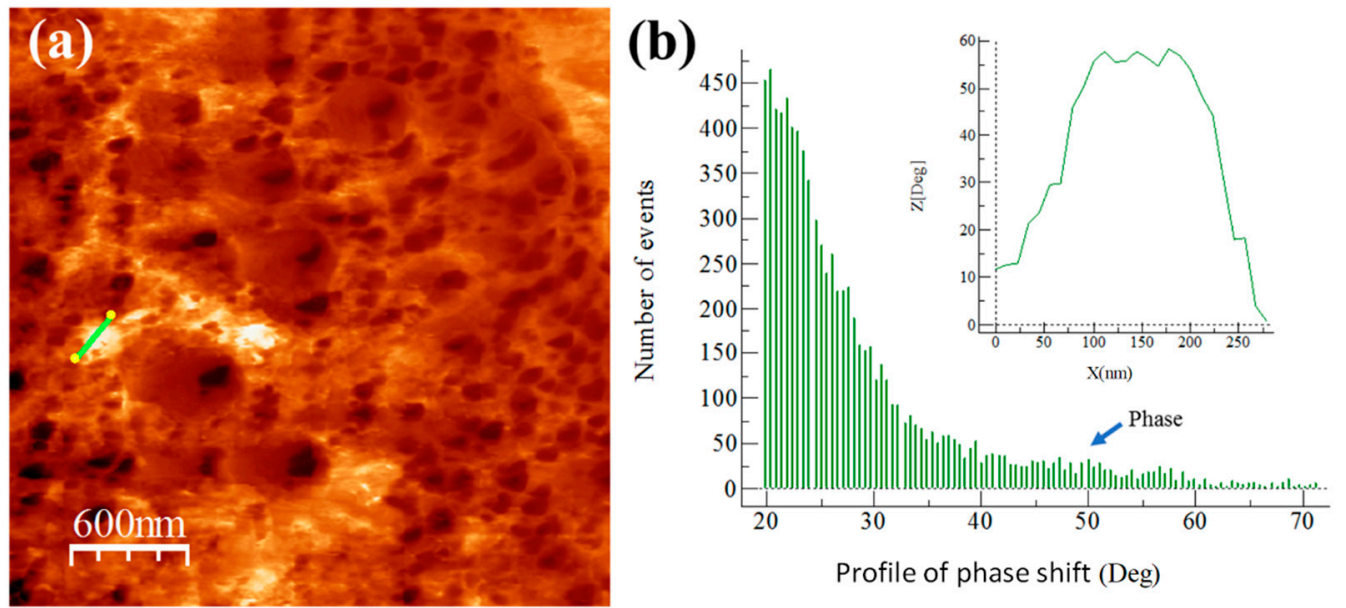

Figure 7. Alp-Mg master compound sample image: (a) AFM tapping mode image and (b) degree distribution profile of phase shift and distribution profile of a corresponding continuous line that crosses the bright area in the phase image (shown inset of the figure).
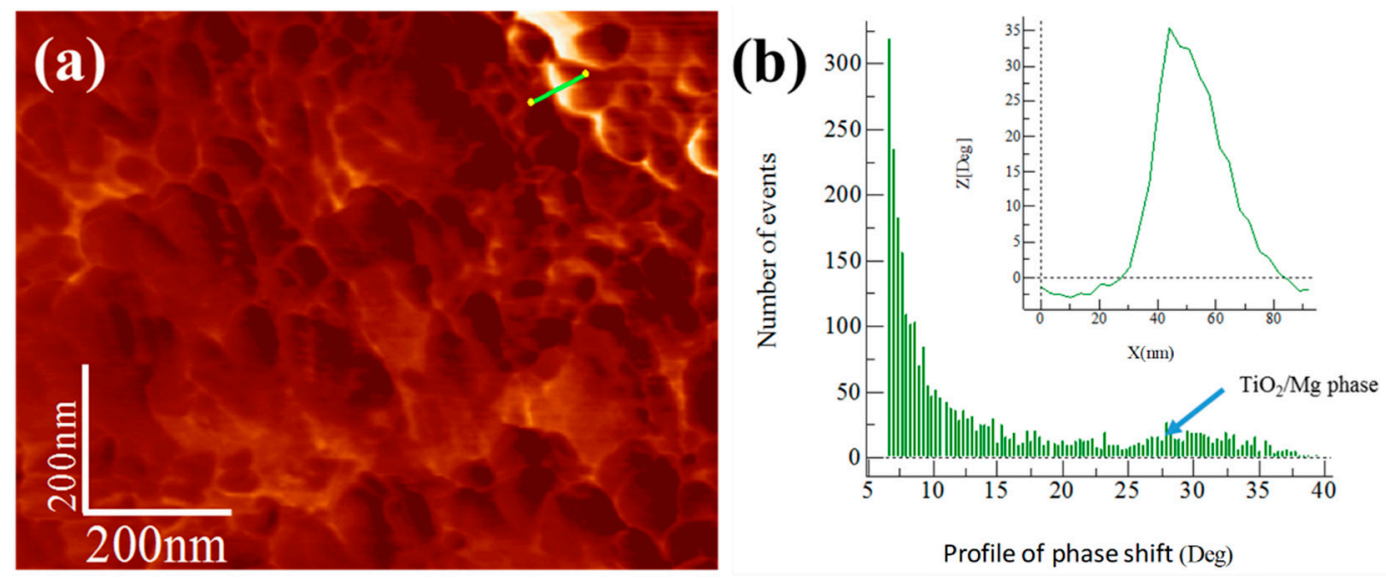

Figure 8. Alp- $-\mathrm{TiO}_{2}$ master compound: (a) AFM tapping mode image and (b) degree distribution profile of phase shift and distribution profile of corresponding continuous line that crosses the bright area in the phase image (shown inset of the figure). 


\subsection{Extruded Samples AFM Phase Characterization}

The AFM images phase and degree distribution profiles of the phase shift for extruded samples are shown in Figures 9-12. The degree distribution profiles of phase shift graphs show the number of events (EN) produced in a specific location by the presence of a second phase. The image phase of the $\mathrm{Al} /$ Ref extruded sample (see Figure 9) shows the presence of clear zones between $\sim 10$ to $\sim 30 \mathrm{~nm}$. These zones produce a phase distribution profile peak located at around $80^{\circ}$. This is verified by correlating the continuous line that crosses the particle in the phase image (see Figure 9a) and the corresponding distribution profile of the phase shift (inset in Figure 9b). The presence of the $\mathrm{Mg}$ phase is related to clear zones, which are similar to the observed in Figure 7 for the Alp-Mg master compound sample image (see Figure 8a,b). For Al/Ref in the extruded sample, these clear zones could correspond mainly to the $\mathrm{Al}-\mathrm{Mg}$ or $\mathrm{MgO}$ precipitates formed during the casting process. The presence of the reinforcement phase in the composites is related to clear zones observable in the phase (see Figures 9-12) whose phase distribution peak is located at around $30^{\circ}$ (similar to the value observed in Figure 8 for the $\mathrm{Alp}-\mathrm{TiO}_{2}$ master compound sample). The solid line that crosses some specific clear zones in phase images coupled with the corresponding distribution profile of the phase shift (inset in Figures) shows the type of particle that produces an angle of about $30^{\circ}$ (phase angle difference between $\mathrm{Al}$ alloy and the reinforcement phase). The event number (EN) of the phase shift produced around $30^{\circ}$ of the phase angle difference between the $\mathrm{Al}$ alloy and the reinforcement phase, which was used as a quantitative parameter of the dispersion of the reinforcement phase into the $\mathrm{Al}$ alloy matrix. The EN and the standard deviation SD of composites are shown in Table 3. The best combination between EN and $\mathrm{SD}$ was observed for the $\mathrm{Al} / \mathrm{TiO}_{2}$ composite, which shows the highest value of $\mathrm{EN}$ and the lowest $\mathrm{SD}$. This corresponds to a higher number of fine particles between $\sim 50$ to $\sim 80 \mathrm{~nm}$ dispersed into the $\mathrm{Al}$ alloy matrix and with less presence of agglomerates, respectively (see Figure 11a). On the other hand, the $\mathrm{Al} / \mathrm{CeO}_{2}$ composites showed the smallest EN value (4700), which means the reinforcing phase is mainly agglomerated. This is manifested in a high standard deviation value ( 3.88). Precipitates in the form of fiber seen in Figure 10a could be of the Al-Ce type. These produce a small peak located at around $60^{\circ}$ (see Figure 10b). Lastly, the Al/C composite shows the highest EN $(17,800)$ value, which means the presence of the fine second phase disperse into the Al-alloy matrix. This phase produced a distribution peak at around $30^{\circ}$ and is related to graphite or the $\mathrm{Al}_{4} \mathrm{C}_{3}$ phase. The other phase, which produces a small signal at around $60^{\circ}$ (see Figure $12 \mathrm{~b}$ ), could correspond to the presence of a relatively small amount of $\mathrm{Al}-\mathrm{Mg}$ or $\mathrm{MgO}$ precipitates formed during the casting process, as explained above. This phase corresponds to the bright particles if the size is around $20 \mathrm{~nm}$ (see Figure 12a).
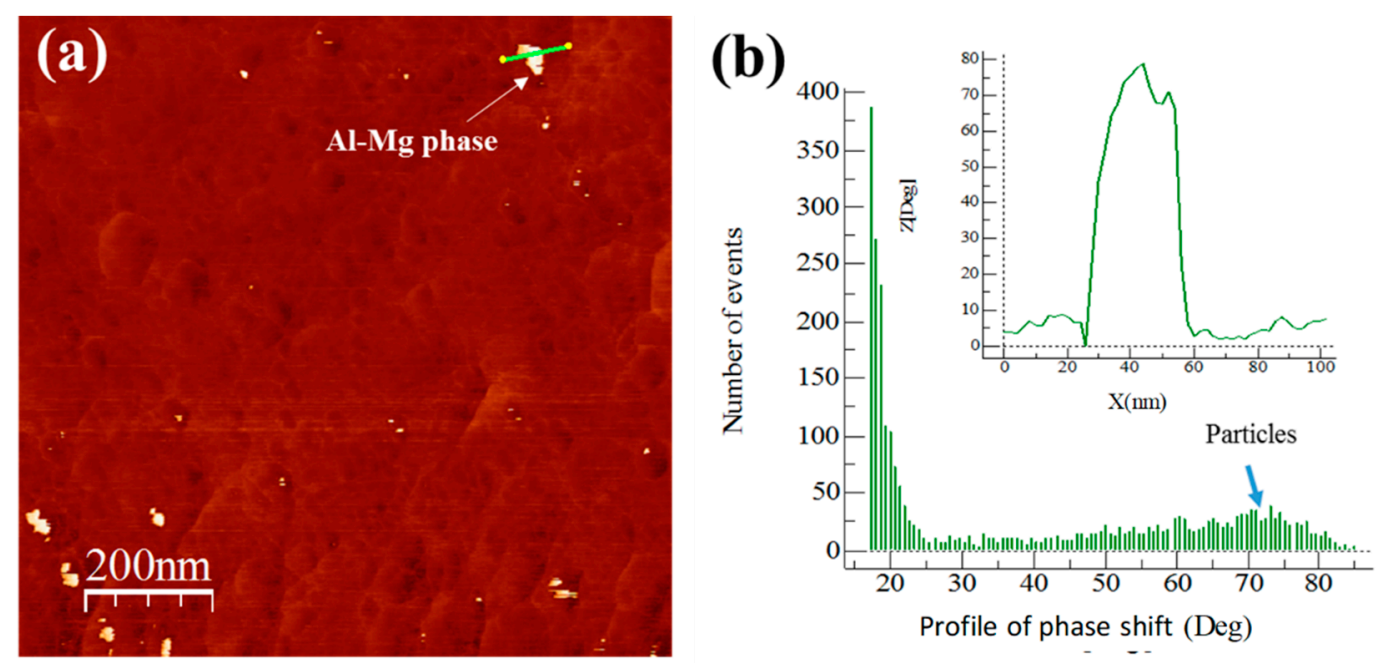

Figure 9. Al/Ref sample: (a) AFM tapping mode image and (b) degree distribution profile of the phase shift and distribution profile of a corresponding continuous line that crosses the bright area in the phase image (shown inset of the figure). 

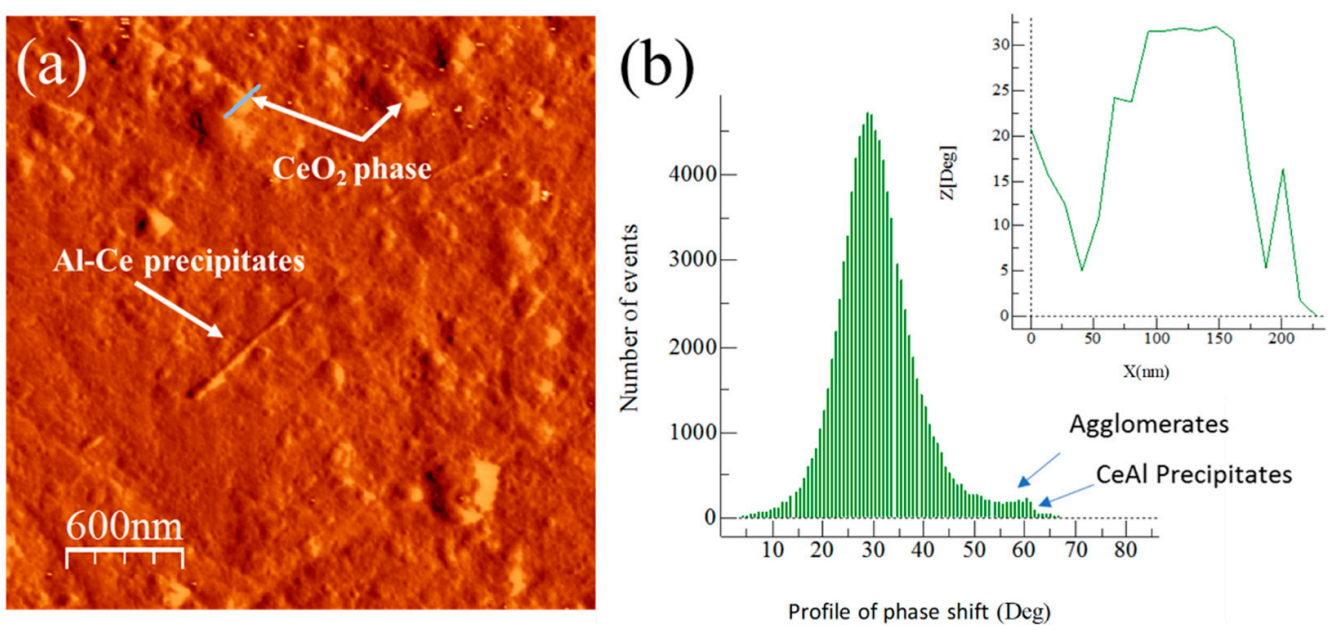

Figure 10. $\mathrm{Al} / \mathrm{CeO}_{2}$ composite: (a) $\mathrm{AFM}$ tapping mode image and (b) degree distribution profile of the phase shift and distribution profile of a corresponding continuous line that crosses the bright area in the phase image (shown inset of the figure).
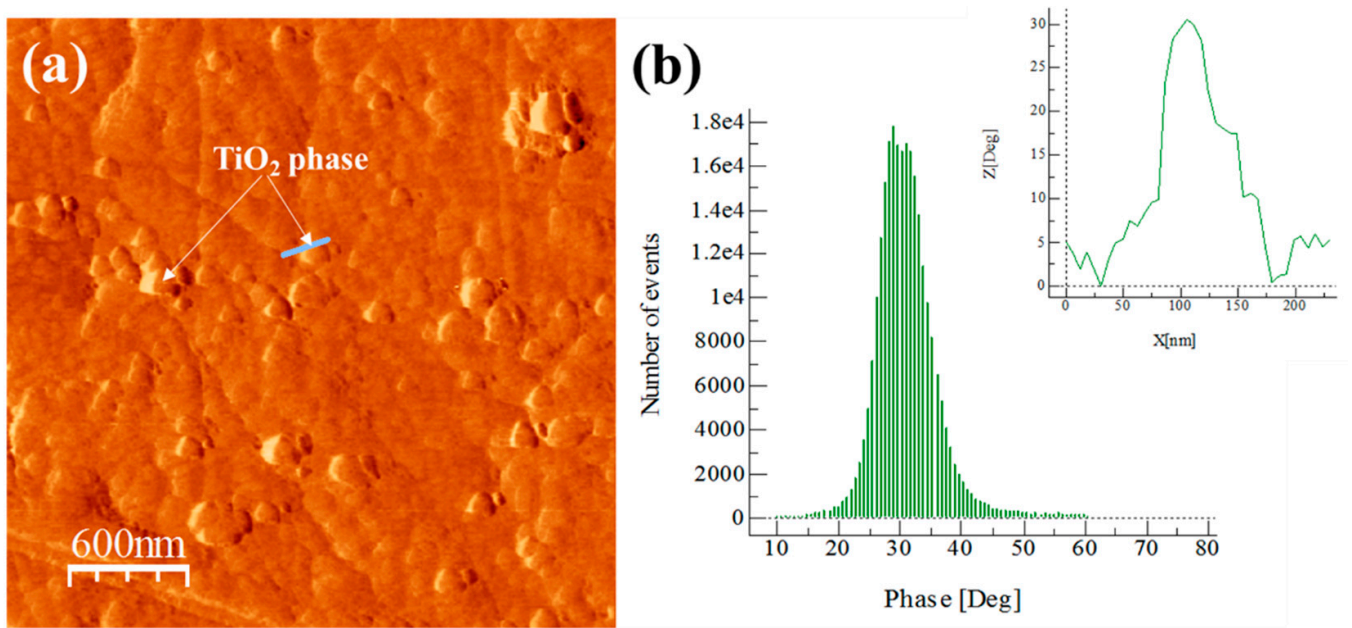

Figure 11. $\mathrm{Al} / \mathrm{TiO}_{2}$ composite: (a) $\mathrm{AFM}$ tapping mode image and (b) degree distribution profile of phase shift and distribution profile of a corresponding continuous line that crosses the bright area in the phase image (shown inset of the figure).
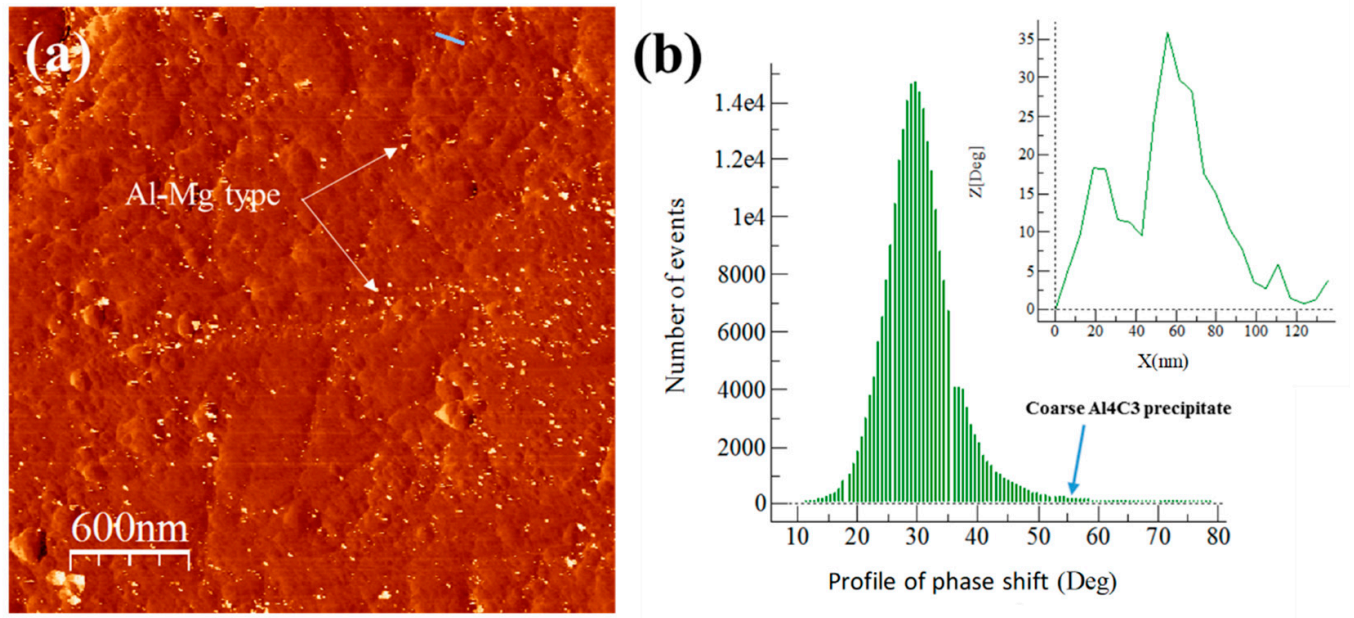

Figure 12. Al/C composite: (a) AFM tapping mode image and (b) degree distribution profile of the phase shift and distribution profile of a corresponding continuous line that crosses the bright area in the phase image (shown inset of the figure). 


\subsection{SEM Characterization}

The SEM images of composites microstructure are shown in Figures $13-15$. The $\mathrm{Al} / \mathrm{CeO}_{2}$ composite microstructure (see Figure 13) where the $\mathrm{CeO}_{2}$ phase with an average size of $\sim 1 \mu \mathrm{m}$ is agglomerated and $\mathrm{Ce}-\mathrm{Al}$ fiber-like intermetallic precipitates are present. Figure 13 also shows a close-up inset view of the $\mathrm{CeO}_{2}$ particles. Figure 14 shows the $\mathrm{Al} / \mathrm{TiO}_{2}$ composite microstructure is observed with a low presence of $\mathrm{TiO}_{2}$ agglomerates of $\sim 250 \mathrm{~nm}$ and some large precipitates of the Al-Mg-Mn phase. The microstructure of the $\mathrm{Al} / \mathrm{C}$ composite is shown in Figure 15. The image shows the presence of the $\mathrm{Al}_{4} \mathrm{C}_{3}$ phase precipitates in both a fiber of a few micrometers $(\sim 3 \mu \mathrm{m}$ long $)$ and rounded particles of around $120 \mathrm{~nm}$ in size (see the close-up inset in the figure). Fine particles of the Al-Mg phase of about $80 \mathrm{~nm}$ were found in the TEM bright-field image into the aluminum matrix of the $\mathrm{Al} / \mathrm{C}$ composite microstructure (see Figure 16).

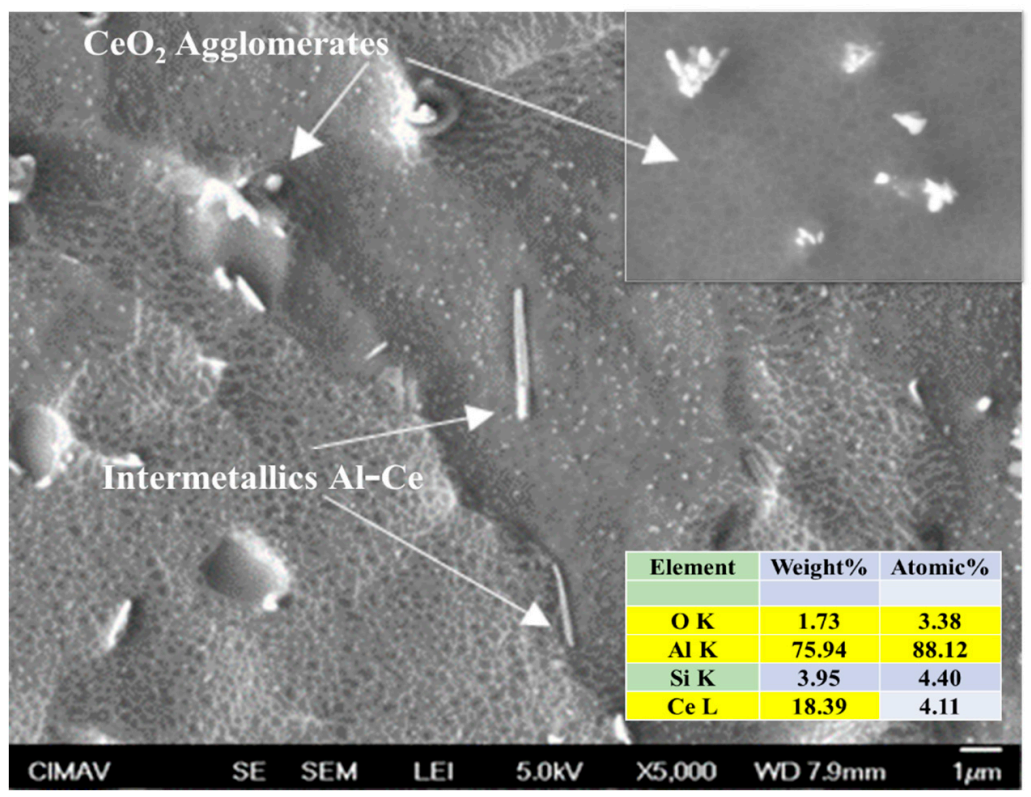

Figure 13. SEM secondary electrons image of the $\mathrm{Al} / \mathrm{CeO}_{2}$ composite.

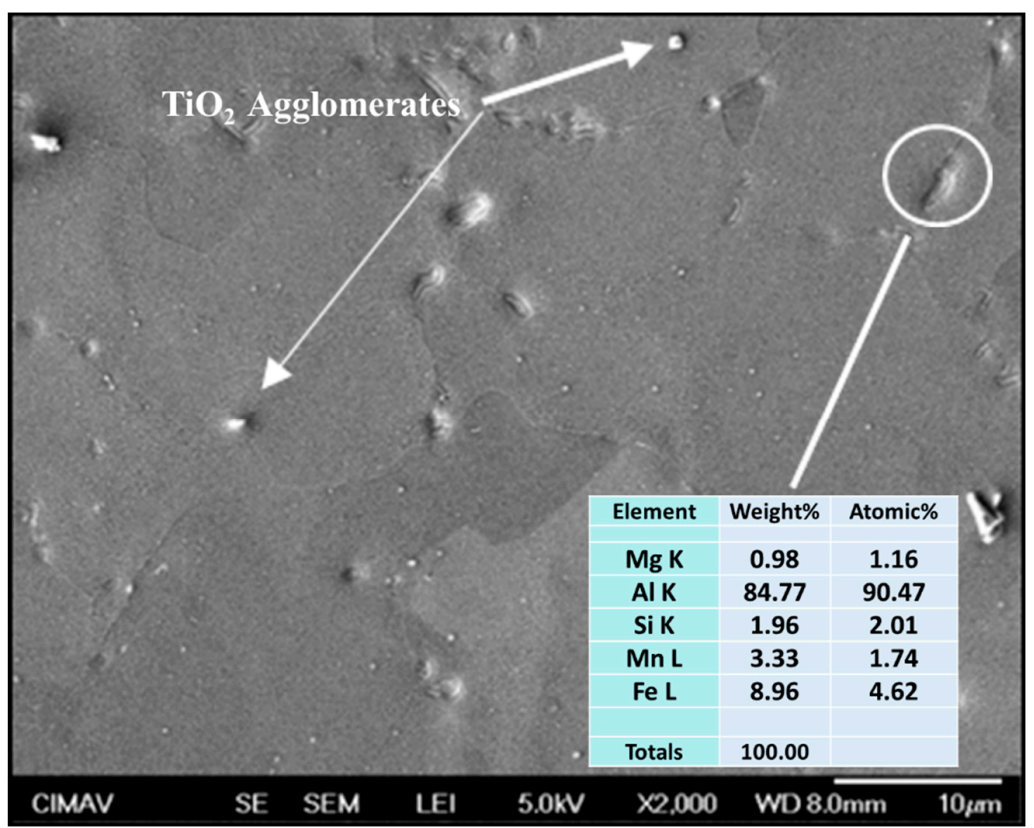

Figure 14. SEM secondary electrons image of the $\mathrm{Al} / \mathrm{TiO}_{2}$ composite. 


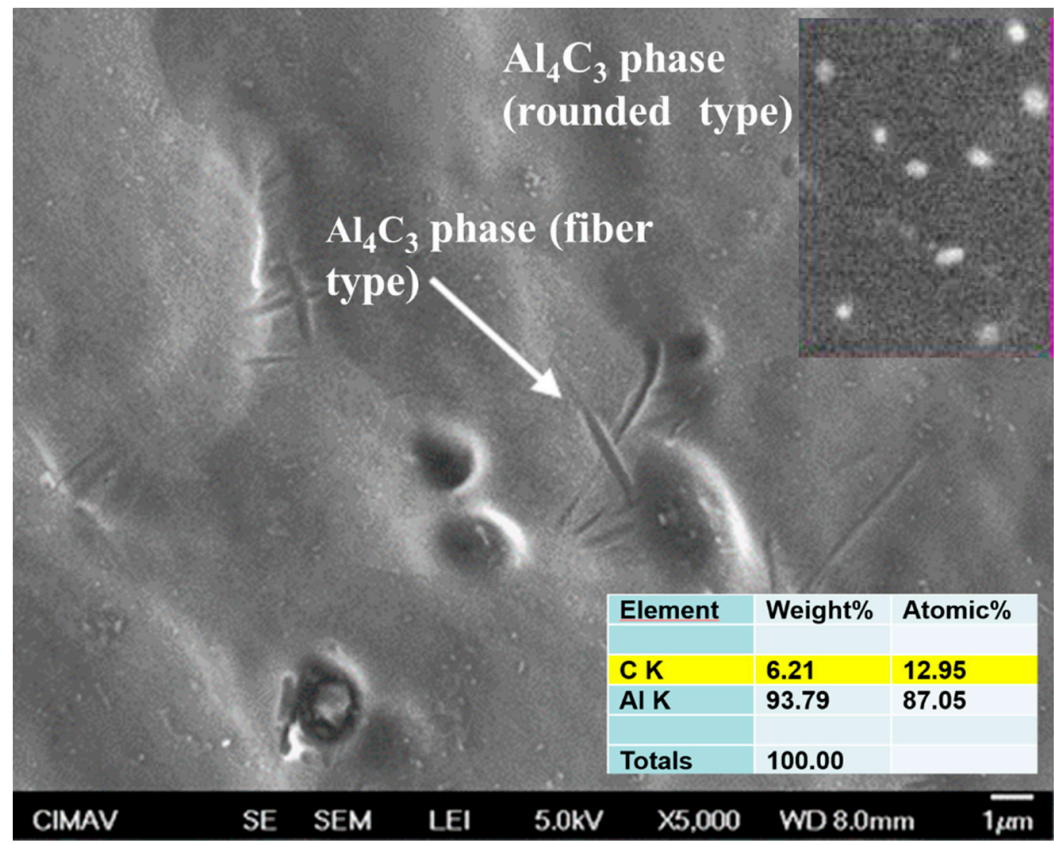

Figure 15. SEM secondary electrons image of the $\mathrm{Al} / \mathrm{C}$ composite.

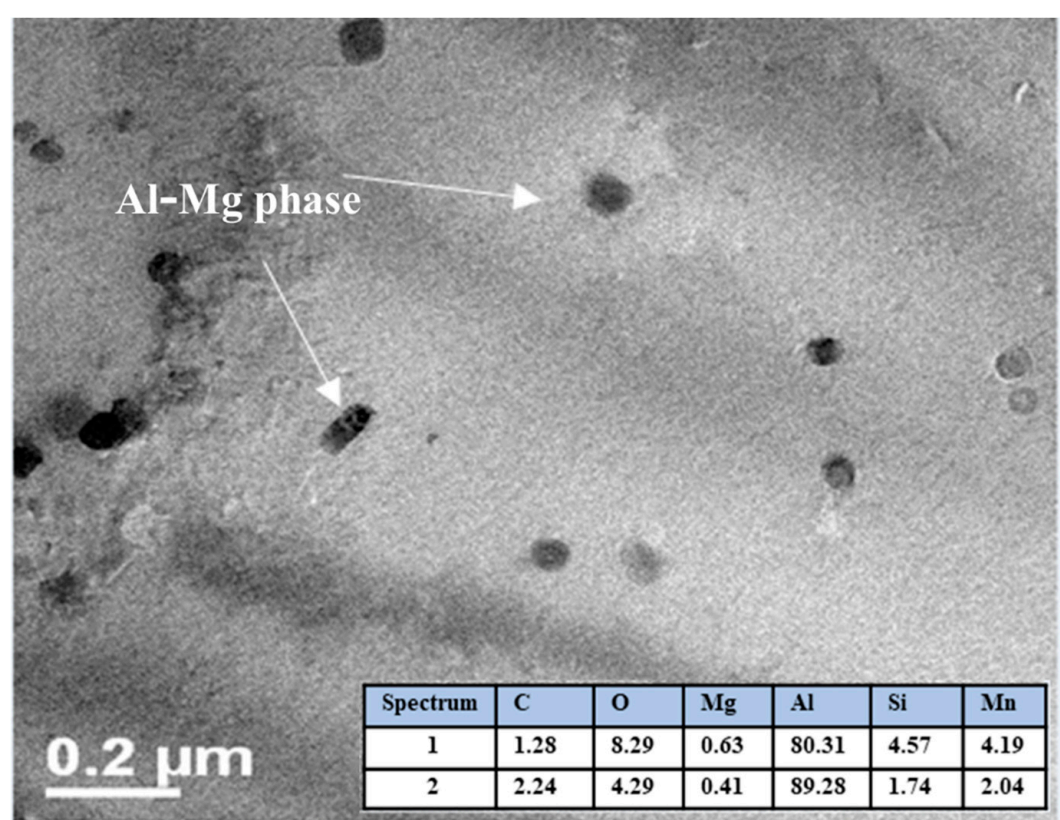

Figure 16. TEM bright field image of the $\mathrm{Al} / \mathrm{C}$ composite.

\subsection{Mechanical Properties Characterization}

Figure 17 shows the graph of the microhardness value as a function of composite samples and the Al/Ref sample. The composites show an evident increase in the microhardness values concerning the Al/Ref sample. The strengthening of the Al-alloy matrix can be attributed mainly to the combination of both a high micro-strain and fine precipitate dispersion. The $\mathrm{Al} / \mathrm{C}$ composite shows the highest microhardness value, with an increase of about $50 \%$ for the Al/Ref sample. These results are in concordance with a high EN value $(26,000)$ from AFM phase analyses depicted in Table 3 . As we see above, a high EN value indicates the presence of a high size and small size quantity of the second phase. $\mathrm{The} \mathrm{Al} / \mathrm{TiO}_{2}$ composite sample showed an increase of about $28 \%$ of microhardness with a marked low dispersion of microhardness values (see Figure 17). The relatively high EN value of $\sim 17,800$ and low SD value of $\sim 2.6$ (see Table 3) from the AFM analyses is also in concordance with the microhardness results. 
Small SD values in both microhardness and phase analyses implicate a low presence of agglomerates and precipitates resulting in better dispersion. The AFM image phase of the $\mathrm{Al} / \mathrm{TiO}_{2}$ composite only shows the presence of one phase (see Figure 11a,b). In the same way, the microstructural analyses SEM revealed a low presence of agglomerates and precipitates of a second phase (see Figure 14). On the other hand, the $\mathrm{Al} / \mathrm{CeO}$ composite sample only showed an increase of only about $18 \%$ with respect to the $\mathrm{Al} / \mathrm{Ref}$ sample, which could be due to the combined effect of a relatively high value of RMS ( 8.69) and low EN ( 4700) value. This results in a low microhardness value. The relative high microhardness dispersion data observed in a graph in Figure 17 correlates with the high SD ( 3.88) found in AFM phase analyses, which means the presence of agglomerates and intermetallic precipitation observed in SEM analyses (see Figure 13). On the other hand, the Al/Ref sample shows values of micro-strains as relatively low ( 0.00014), high RMS values $(\sim 12.79 \mathrm{~nm})$, and the EN value at $30^{\circ}$ of the phase distribution peak found in his sample was practically zero (see Table 3 ). This means that the reinforcing phase is not present. The relatively high mechanical properties of the $\mathrm{Al} / \mathrm{Ref}$ sample could be attributed to the presence of the small precipitates of $\mathrm{Al}-\mathrm{Mg}$ o $\mathrm{MgO}$ phases observed in the phase peak distribution at $\sim 70^{\circ}$ of AFM analyses.

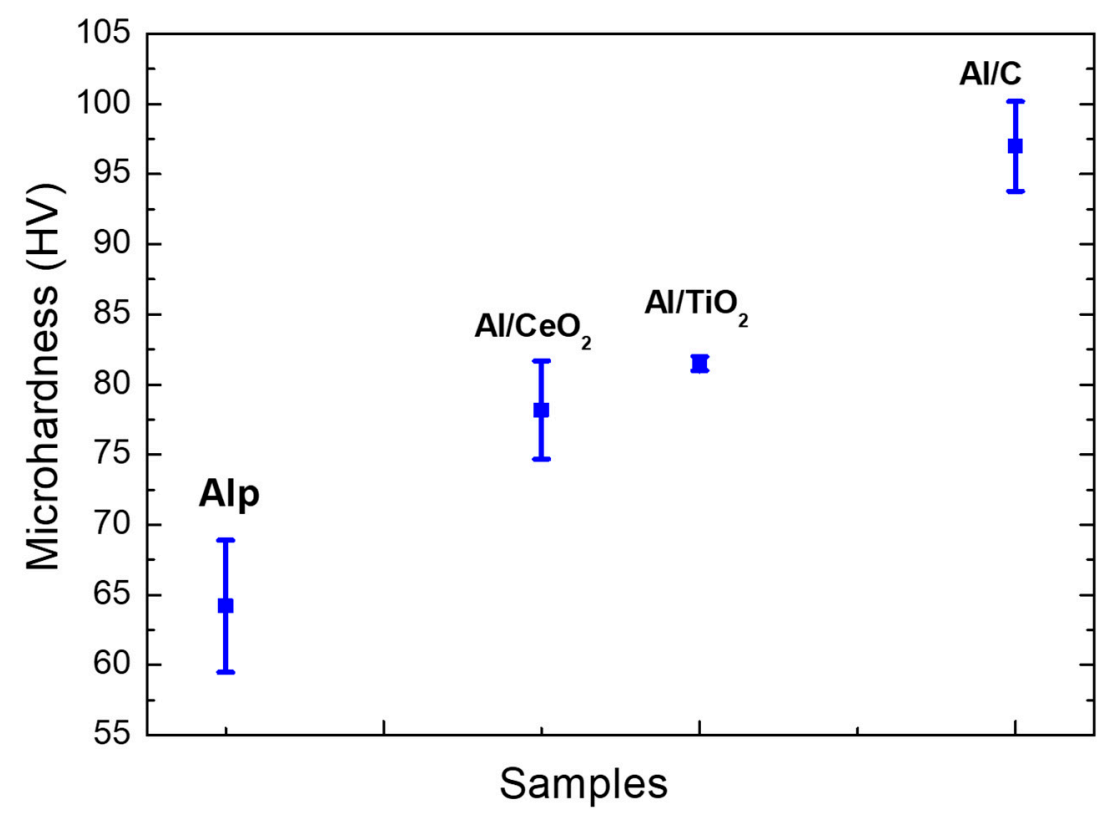

Figure 17. Microhardness values as a function of composite types.

\section{Conclusions}

Nanocomposites with a different type of nanoparticles using Recycled Aluminum (3XXX Series Al alloy) from beverage cans has been produced by combining the powder metallurgy and the stir casting method. The microstructure of the extruded samples evaluated by XRD revealed a nanostructured state and the presence of a lattice micro-strain product of the combined effect of the extrusion process and dispersion of the hard particles into $\mathrm{Al}$ alloy. The study conducted to estimate the roughness on the surface revealed a roughness surface at a nanoscale level in all the samples. However, for the composites, the presence of the reinforcement further decreased the roughness level displacing the peak of the height distribution profile to the left. The level of the roughness surface was in concordance with lattice micro-strain values found in XRD analyses. The AFM phase analyses revealed the presence of agglomerates and coarse precipitates (quantified by EN and SD parameters), which negatively affected the microhardness values. A close correlation between microhardness and micro-strain lattice values, together with roughness surface analyses, was observed. Among all, the Al-C composite showed the best mechanical properties, which showed better integration and dispersion of the reinforcement coupled with the presence of fine precipitation of $\mathrm{Al}_{4} \mathrm{C}_{3}$. Among different factors affecting the 
capability of the reinforcement to be homogeneously dispersed throughout the $\mathrm{Al}$ matrix during the casting process, is the low wettability of ceramic nano-particles combined with the small size of the reinforcement particle, which tend to form agglomerates. This work proposes a method to evaluate the behavior of the reinforcement in a stir casting process in the nano-MMC's production.

Author Contributions: Conceptualization, V.G.-O. and A.S.-B.; methodology, V.G.-O. and A.S.-B.; software, I.R.-O.; validation, V.G.-O., A.S.-B. and R.C.-S.; formal analysis, A.S.-B.; investigation, V.G.-O.; resources, I.E.-G.; data curation, A.S.-B.; writing—original draft preparation, V.G.-O.; writing—review and editing, A.S.-B.; visualization, M.S.-B.; supervision, J.B.-C.; project administration, A.S.-B. and V.G.-O. All authors have read and agreed to the published version of the manuscript.

Funding: This research was funded by Universidad Tecnológica de Chihuahua Sur.

Conflicts of Interest: The authors declare no conflict of interest.

\section{References}

1. Khakbiz, M.; Akhlaghi, F. Synthesis and structural characterization of $\mathrm{Al}-\mathrm{B}_{4} \mathrm{C}$ nano-composite powders by mechanical alloying. J. Alloy. Compd. 2009, 479, 334-341. [CrossRef]

2. Abdoli, H.; Asgharzadeh, H.; Salahi, E. Sintering behavior of Al-AlN-nanostructured composite powder synthesized by high-energy ball milling. J. Alloy. Compd. 2009, 473, 116-122. [CrossRef]

3. Birol, Y. Response to thermal exposure of the mechanically alloyed Al/C powder blends. J. Alloy. Compd. 2008, 460, L1-L5. [CrossRef]

4. Arik, H. Effect of mechanical alloying process on mechanical properties of $\alpha-\mathrm{Si}_{3} \mathrm{~N}_{4}$ reinforced aluminum-based composite materials. Mater. Des. 2008, 29, 1856-1861. [CrossRef]

5. Santos-Beltrán, A.; Goytia-Reyes, R.; Morales-Rodriguez, H.; Gallegos-Orozco, V.; Santos-Beltrán, M.; Baldenebro-Lopez, F.; Martínez-Sánchez, R. Characterization of $\mathrm{Al}-\mathrm{Al}_{4} \mathrm{C}_{3}$ nanocomposites produced by mechanical milling. Mater. Charact. 2015, 106, 368-374. [CrossRef]

6. Martínez-Sánchez, R.; Reyes-Gasga, J.; Caudillo, R.; García-Gutierrez, D.I.; Márquez-Lucero, A.; Estrada-Guel, I.; Mendoza-Ruiz, D.C.; José Yacaman, M. Mechanical and microstructural characterization of aluminum reinforced with carbon-coated silver nanoparticles. J. Alloy. Compd. 2007, 438, 195-201. [CrossRef]

7. Casati, R.; Vedani, M. Metal Matrix Composites Reinforced by Nano-Particles-A Review. Mater. Today Proc. 2014, 4, 65-83. [CrossRef]

8. Thostenson, E.T.; Li, C.; Chou, T.-W. Nanocomposites in context. Compos. Sci. Technol. 2005, 65, 491-516. [CrossRef]

9. Sajjadi, S.A.; Ezatpour, H.R.; Torabi Parizi, M. Comparison of microstructure and mechanical properties of A356 aluminum alloy/ $\mathrm{Al}_{2} \mathrm{O}_{3}$ composites fabricated by stir and compo-casting processes. Mater. Des. 2012, 34, 106-111. [CrossRef]

10. Santos-Beltrán, A.; Gallegos-Orozco, V.; Reyes, R.G.; Miki-Yoshida, M.; Estrada-Guel, I.; Martínez-Sánchez, R. Mechanical and microstructural characterization of dispersion strengthened Al-C system nanocomposites. J. Alloy. Compd. 2010, 489, 626-630. [CrossRef]

11. Mazahery, A.; Abdizadeh, H.; Baharvandi, H.R. Development of high-performance $\mathrm{A} 356 / \mathrm{nano}^{-}-\mathrm{Al}_{2} \mathrm{O}_{3}$ composites. Mater. Sci. Eng. A 2009, 518, 61-64. [CrossRef]

12. Chen, F.; Chen, Z.; Mao, F.; Wang, T.; Cao, Z. TiB 2 reinforced aluminum based in situ composites fabricated by stir casting. Mater. Sci. Eng. A 2015, 625, 357-368. [CrossRef]

13. Dehghan Hamedan, A.; Shahmiri, M. Production of A356-1 wt \% SiC nanocomposite by the modified stir casting method. Mater. Sci. Eng. A 2012, 556, 921-926. [CrossRef]

14. Ezatpour, H.R.; Sajjadi, S.A.; Sabzevar, M.H.; Huang, Y. Investigation of microstructure and mechanical properties of Al6061-nanocomposite fabricated by stir casting. Mater. Des. 2014, 55, 921-928. [CrossRef]

15. Suprapto, W. Effect recycled aluminium structures of metallurgycal and melt efficiency. IOP Conf. Ser. Mater. Sci. Eng. 2019, 494, 012085. [CrossRef]

16. Moses, J.J.; Dinaharan, I.; Sekhar, S.J. Prediction of influence of process parameters on tensile strength of AA6061/TiC aluminum matrix composites produced using stir casting. Trans. Nonferr. Met. Soc. China 2016, 26, 1498-1511. [CrossRef] 
17. Krishnan, P.K.; Christy, J.V.; Arunachalam, R.; Mourad, A.H.I.; Muraliraja, R.; Al-Maharbi, M.; Murali, V.; Chandra, M.M. Production of aluminum alloy-based metal matrix composites using scrap aluminum alloy and waste materials: Influence on microstructure and mechanical properties. J. Alloy. Compd. 2019, 784, 1047-1061. [CrossRef]

18. Tahamtan, S.; Halvaee, A.; Emamy, M.; Zabihi, M.S. Fabrication of Al/A206- $\mathrm{Al}_{2} \mathrm{O}_{3}$ nano/micro composite by combining ball milling and stir casting technology. Mater. Des. 2013, 49, 347-359. [CrossRef]

19. Elango, G.; Raghunath, B.K. Tribological Behavior of Hybrid (LM25Al $\left.+\mathrm{SiC}+\mathrm{TiO}_{2}\right)$ Metal Matrix Composites. Procedia Eng. 2013, 64, 671-680. [CrossRef]

20. Irhayyim, S.S.; Hammood, H.S.; Abdulhadi, H.A. Effect of nano-TiO 2 particles on mechanical performance of Al-CNT. AIMS Mater. Sci. 2019, 6, 1124-1134. [CrossRef]

21. Malaki, M.; Xu, W.; Kasar, A.K.; Menezes, P.L.; Dieringa, H.; Varma, R.S.; Gupta, M. Advanced Metal Matrix Nanocomposites. Metals 2019, 9, 330. [CrossRef]

22. Xue, J.; Wang, J.; Han, Y.; Chen, C.; Sun, B. Behavior of $\mathrm{CeO}_{2}$ additive in in-situ $\mathrm{TiB}_{2}$ particles reinforced 2014 Al alloy composite. Trans. Nonferr. Met. Soc. China 2012, 22, 1012-1017. [CrossRef]

23. Mohammed, H.; Reddy, M.P.; Ubaid, F.; Shakoor, A.; Mohamed, A.M.A. Structural and mechanical properties of $\mathrm{CeO}_{2}$ reinforced $\mathrm{Al}$ matrix nanocomposites. Adv. Mater. Lett. 2018, 9, 602-605. [CrossRef]

24. Horcas, I.; Fernandez, R.; Gomez-Rodriguez, J.M.; Colchero, J.; Gomez-Herrero, J.; Baro, A.M. WSXM: A software for scanning probe microscopy and a tool for nanotechnology. Rev. Sci. Instrum. 2007, 78, 013705. [CrossRef] [PubMed]

25. Habibnejad-Korayem, M.; Mahmudi, R.; Poole, W.J. Enhanced properties of Mg-based nano-composites reinforced with $\mathrm{Al}_{2} \mathrm{O}_{3}$ nano-particles. Mater. Sci. Eng. A 2009, 519, 198-203. [CrossRef]

26. Zhu, J.-Q.; Liu, X.; Yang, Q.-S. Dislocation-blocking mechanism for the strengthening and toughening of laminated graphene/Al composites. Comput. Mater. Sci. 2019, 160, 72-81. [CrossRef]

27. Khodabakhshi, F.; Simchi, A.; Kokabi, A.H.; Gerlich, A.P.; Nosko, M. Effects of post-annealing on the microstructure and mechanical properties of friction stir processed $\mathrm{Al}-\mathrm{Mg}-\mathrm{TiO}_{2}$ nanocomposites. Mater. Des. 2014, 63, 30-41. [CrossRef]

28. Gadelmawla, E.S.; Koura, M.M.; Maksoud, T.M.A.; Elewa, I.M.; Soliman, H.H. Roughness parameters. J. Mater. Process. Technol. 2002, 123, 133-145. [CrossRef]

(C) 2020 by the authors. Licensee MDPI, Basel, Switzerland. This article is an open access article distributed under the terms and conditions of the Creative Commons Attribution (CC BY) license (http://creativecommons.org/licenses/by/4.0/). 